\title{
4. Making research more relevant to policy: evidence and suggestions ${ }^{1}$
}

\author{
Meredith Edwards
}

\section{Dimensions of the research-policy problem}

Dr Peter Shergold, in launching a book on Ideas and Influence (2005), referred to the 'fragility of relationships' as it applies to public policy and the social sciences. He observed that ' $[t]$ he relationships between social science and public policy, and between academic and public servant, are ones of the utmost importance'. He went on to say, however: 'They are not, I think, in particularly good shape' (Shergold 2005:2). He elaborated little but could have gone on to mention, as others have (for example, Blunkett 2000), that academic research often deals with issues that are not central to or really relevant to policy debates, and can fail to take the reality of people's lives into account in setting research questions. Conversely, when research tries to be relevant, it can be seen as being driven by ideology dressed up as intellectual inquiry. And a frequent complaint is the lack of timeliness in academic research. Such are the frustrations of many policymakers.

The perspective of academic researchers has been well put by Professors Saunders and Walter in the introduction to their book, Ideas and Influence (2005:3): there is a lack of attention by policy practitioners to the subtleties and qualifications of their research findings and a fear that 'those driving policy are seeking to justify actions already decided by "cherry-picking" from among the available evidence with little regard for the robustness or validity of the material selected'. They go on to point out that 'those involved in policy development often have little idea of how or where existing research can contribute, or what is needed to help resolve outstanding issues' (Saunders and Walter 2005:13). To this could be added an anti-intellectual approach sometimes formed within governments; a risk-averse attitude by public servants to findings that could embarrass the

1 This chapter was prepared while the author was also chairing a review of the research program of the Australia New Zealand School of Government (ANZSOG). Some of the material in this chapter therefore overlaps that contained in the review document. 
minister; the short time frames under which governments operate; and a lack both of respect for the independence of researchers and of incentives needed for researchers to produce policy-relevant material (Edwards 2004:3).

Journalist Paul Kelly (2005:2), in exploring this uneasy relationship, considers the two cultures traditionally foreign worlds; he describes the researcher as the quintessential specialist and the politician as the ultimate generalist. In considering next steps, Kelly (2005:2) goes on: 'Research has got to throw forward to policy. Research has got to be more geared to policy needs, to be effective. The first step on the pathway is to stimulate debate by engaging the policy makers.' Another step he identifies is having a relevant public sector agency involved in the interaction of policymakers and researchers.

So, while the problem of the research-policy nexus is clear, the relationship is quite complex when it comes to being practical about the next steps. A tailored approach, sensitive to the context for each policy problem, is likely to be required if research is to be effectively harnessed; and each issue might require different types of research output or engagement, depending on the stage in the development of policy. Relatedly, the research needed could be descriptive, analytical, diagnostic, theoretical or prescriptive (Solesbury 2002:94). Research could be used directly or simply to raise awareness and start to shape policy thinking through ideas, theories and concepts (Nutley et al. 2007:2). And research can range from traditional academic publications through to a broader interpretation, including, for example, stakeholder consultations and interactive policy/research outputs.

\section{What works best?}

Some evidence is starting to emerge about mechanisms that seem to work best for people in the public service who deal with policy issues and who want to engage researchers in solving policy problems. While the evidence to date is not robust, recent work in the United Kingdom by Nutley et al. (2007), based on extensive evaluations, concludes the following about successful research strategies:

One of the best predictors of research use is...the extent and strength of linkages between researchers and policy makers or practitioners. Personal contact is crucial, which may be informal and ad hoc, through email exchanges or telephone conversations, or else more structured and formal, for example at scheduled meetings or shared workshops. We have seen, individual policy makers often rely on a personal network of researchers to identify key findings and as a 'sounding board' for ideas. These interpersonal routes for getting research into policy seem 
particularly effective...Above all, however, studies suggest that it is face-to-face interactions that are the most likely to encourage policy and practice use of research. (Nutley et al. 2007:74)

The more traditional linear relationship from research output to policy decisions (and knowledge transfer) is being seen as generally inferior to more interactive approaches to enhancing the use of research; useful research is moving from simply being a stand-alone activity to being part of the policy process.

In addition, the evidence is pointing to

- the value of collective or team approaches in the use of research and decision making as distinct from the tradition of focusing on the output of individual researchers

- the value of intermediation where many voices and agencies are brought into policy processes

- the value of a broader definition of research to encompass a range of types of knowledge generation and dissemination (Nutley et al. 2007).

\section{Some practical suggestions}

There are interrelated demand (from governments) and supply (from researchers) issues involved in achieving successful interactions between research and policy, which need to be addressed.

\section{For academics}

The way in which people within government bureaucracies operate sometimes has to be seen to be believed! The pace at which they work, the brevity of the briefs they prepare for ministers and the constraints they sometimes face in terms of the ideological framework they need to work within are just a few of the issues they face. Hence, working on secondment within government for a fixed period is an excellent way for academics to gain context and understanding of what is needed if they want to have an influence. The form of secondment could be as an 'academic in residence' on a particular project or in a position that requires greater interaction. Either way, the learning experience can be considerable as well as leading to some influence.

A good example is given below in the case study on 'Working Nation', which deals with the issue of long-term unemployment (LTU), which was of serious policy concern in 1993-94. The case shows the influence of an academic, Professor Bruce Chapman, who had written relevant articles but, importantly, 
also had developed a network of public servants and political advisers within government who knew of his ideas. These people called on him to take a more active role within government to assist them in bringing labour market policies into action. He worked as a consultant for a time, sat on a key committee and later moved to work as an adviser on labour market issues within the Prime Minister's Office. He returned to academia at the end of the exercise.

\section{For public servants}

One of the calls I hear from senior public servants is their problem in accessing relevant knowledge; they need to know who is doing what research and how to access that when they want it. This is the case particularly when the required knowledge crosses disciplines and is needed to assist with whole-of-government issues.

Therefore, some form of intermediary structure or organisation could be needed to act as a broker or a 'clearing house'. Such a 'knowledge-brokering' organisation might assist public servants locate the research or access researchers when needed and could more actively assist in organising round tables involving public servants and academics, if not others, on key policy issues. Being such a 'boundary organisation' is one of the key roles of ARACY.

Other suggestions include: supplementing funding for doctoral students who are researching relevant topics; providing academics with access to governmentheld data; and bringing in academic experts as well as community representatives to sit on task forces on priority issues. New Zealand has an arrangement whereby researchers are called on to attend forums on emerging issues to assist government 'see above the horizon' on issues they or the researchers choose. In the United Kingdom, there has been some success in seconding outsiders, including academics, to be part of project teams for a specific period (Mulgan 2003:18).

\section{Case study}

Nutley et al. (2007:132) discuss at some length five prevalent and important mechanisms for improving the use of research. These often overlap or are used together.

- Dissemination: presenting or circulating research findings targeted to the potential audience.

- Interaction: developing stronger links and collaborations across the sectors. 
- Social influence: relying on those with influence, such as experts and peers, to inform and persuade individuals about the research and its value.

- Facilitation: enabling the use of research, whether that is technically, financially or in other ways.

- Incentives and reinforcements: using rewards and other means to reinforce desired behaviours.

These mechanisms, particularly the first three, certainly proved important to me when I was Deputy Secretary in the Department of Prime Minister and Cabinet and chaired a task force of officials in 1993-94 involved in developing the 'Working Nation' package of measures. In writing up this case study (Edwards 2001:176), I noted as a concluding observation that 'especially crucial in this case was the role of academics in producing policy-relevant knowledge on the nature and dimensions of the LTU [long-term unemployment] problem'.

In this case study, the influence of knowledge transfer from academic (and other non-government) research to practice can be seen best in the early stages of the development of policies after the election in 1993 - particularly in

- identifying the problem and getting the issue of long-term unemployment on the political agenda

- the stage of policy analysis: collecting and analysing data, identifying key issues and formulating relevant options.

\section{Problem identification}

Several factors led to the issue of long-term unemployment being put firmly on the agenda, but a crucial contribution came from three ANU academics who drew attention to the urgency of the problem. Two of the researchers were the 'producers' of the knowledge (Junankar and Kapuscinksi). The third, Professor Bruce Chapman, wrote about the issue but also was key to its dissemination. The dissemination occurred effectively because Chapman was part of a network of people he had met in 'earlier lives', through his involvement as 'architect' of the Higher Education Contribution Scheme (HECS) and who now were influential in ministerial offices and in the relevant department. Immediately after the Keating government's victory in the 'un-winnable election' in 1993, those in this network of people were talking to each other (see Edwards 2001:14 ff. for more detail; for Chapman's role, see Appendix 4.1).

Before moving to the Department of Prime Minister and Cabinet, I was in the then Department of Employment, Education and Training (DEET) running the Economic Analysis Division. I could see that senior people within the department and most ministerial staff needed some convincing of the seriousness 
of the problem. Chapman was invited to present his findings at a seminar of carefully selected people, including the head of the department, his deputies and relevant ministerial advisers, including from the Prime Minister's Office. The way in which Chapman presented the case with his analysis and graphs certainly convinced our Secretary and his deputies. Processes snowballed from there, including DEET hiring Chapman as a consultant to write up the issue in more detail, especially about who were the long-term unemployed-a gap in our knowledge at the time.

\section{Policy analysis}

This was not a process involving the usual interdepartmental committees. Instead, a high-level committee, the Committee on Employment Opportunities (CEO), was set up within the Department of Prime Minister and Cabinet (PM\&C) to oversee the policy to alleviate long-term unemployment. Its membership was critical to its success. The committee, reporting to the Prime Minister, could not afford to come up with solutions at odds with the broad direction of government policy, so it was chaired by the Secretary of the Department of PM\&C, Dr Michael Keating, and a senior policy adviser within the Prime Minister's Office was on it. It also included two other heads of department, one member of the non-government sector and two academics, with Chapman as an observer. It was served by a task force, which I headed and which had as its first main task identifying gaps in knowledge on the nature and composition of long-term unemployment and attempting to fill them, including commissioning papers from academic researchers and community groups, such as the Brotherhood of St Laurence and the Australian Council of Social Services (ACOSS).

One excellent example of the interaction of the sectors occurred between Treasury officials and the academics on the CEO on a purely technical but politically significant issue on which there was no hard evidence. There was considerable disagreement on the extent to which government intervention to assist the long-term unemployed would reduce the unemployment rate. A one-day workshop in which there was intense debate between bureaucrats and academics followed (for more detail, see Edwards 2001:153-4). Chapman's assessment of this process was:

In terms of the relevance of research to the policy process, this was a critical example...Things would have gone quite differently if we had not had the technical expertise to present these arguments, and if Treasury had had the superior expertise to destroy our arguments. It was a very academic exercise, but behind this, politics and ideology were critical. (In Edwards 2001:154) 
More examples from this case study could be given of the benefits of interaction between academic researchers (working from the outside as well as inside of government), on the one hand, and senior officials, on the other; and of the important role of business, unions and community groups, as well as the unemployed themselves, in interacting with government in the policy process. The above examples should suffice, however, to illustrate the importance of dissemination and interaction in the research process, as well as the benefits of influence through established networks.

It could be argued that circumstances were favourable to using research in this case given that the demand side - that is, the government-was responsive. That certainly helped, but does not detract from the need to look beyond the academic article and beyond the linear process of transferring knowledge for effective impact.

\section{Conclusion}

It is not much use producing knowledge that could be relevant if it is not also effectively disseminated. Yet many academics are focused on producing articles and then lose interest beyond that point, preferring to move onto the next article, despite potential policy or practitioner relevance. Therefore there is a need for many forms of intermediary agencies to connect producers to users. A linear relationship between these two - as this chapter has demonstrated-might not be sufficient, however, if there is to be policy influence from researchers. Interactive processes seem to be a key ingredient.

Interaction in developing policy increasingly needs to include groups other than academic researchers. Although this chapter has focused mainly on the relationship between academics and public servants, the importance of the interaction of both these sets of players with broader community interests should not be neglected. In the case study above, community and business groups were important in research and the consultation process. In an environment of more engagement by governments with their communities, academics cannot afford not to be closely in tune with citizen views if they wish to influence policy and practice. 


\section{Appendix 4.1}

\section{Recollections of Labor policy advisers, March 1993}

\section{Bruce Chapman, academic seconded into government}

I can remember Tom Burton, the journalist, calling me up and asking me what happened the day after the election...I can remember phone calls with various people - Mary Ann [O'Loughlin], maybe Meredith [Edwards], certainly David Phillips - who said we must do something about long-term unemployment. They knew it was there; maybe they were getting information from the department as well as other people from Keating's office, but it had to be addressed. But because they had seen me as so involved in the research side they wanted to discuss the possibility of something happening. My involvement started with personal liaison with those people. David Phillips said, 'Bring all your pictures that you have been complaining about to me and to Mary Ann and Meredith, and come and have dinner with [Employment Minister, Kim] Beazley', which I did, and they explained why long-term unemployment was an economic issue.

\section{Mary Ann O'Loughlin, social policy adviser to Prime Minister Paul Keating}

The Sunday after the election I thought, if Bruce Chapman is right, then we - meaning the government - are politically in deep, deep trouble. By the time of the next election, long-term unemployment would be terrible - even if the recovery came through, even if short-term unemployment lifted up, long-term unemployment would be sticking out like the proverbial sore thumb; and for a Labor government that is about the worst thing you can get: this would be particularly bad on the Labor Government's credentials. So it is definitely Bruce's work that put this issue on the agenda and definitely a political imperative about winning an election.

\section{David Phillips, senior adviser to Kim Beazley, Minister for Employment, Education and Training.}

Very early on I had the sense that we had won the unwinnable election and we had gone into that election almost silent on unemployment. We had cobbled together a bit of a policy but we all knew that it was inadequate. So I and obviously others, had a very strong sense that something had to be done about that now that we had won. I rang Bruce 
quite early in the piece and simply said 'What have you been doing on unemployment and long-term unemployment?' I can remember trying to draw the Beveridge Curve as he described it to me over the telephone. He said 'You can shift it to the left or the right...' I then either spoke to Mary Ann or I had another conversation with Bruce, but that set the ball rolling. The significance of the Beveridge Curve was not so much any of the theory behind it but the fact that here there was, for the first time, an argument that said there can be positive economic returns from doing something about long-term unemployment.

Adapted from Edwards (2001:145-6).

\section{References}

Australia New Zealand School of Government (ANZSOG) Research Reference Group 2007, Enhancing ANZSOG's Contribution to Better Government: Future research directions, October, Australia New Zealand School of Government, The Australian National University, Canberra, viewed 3 May 2010, <http:// www.anzsog.edu.au/content.asp?pageId $=21>$

Blunkett, David 2000, Influence or irrelevance: can social science improve government?, Speech to a meeting convened by the Economic and Social Research Council, February.

Edwards, Meredith 2001, Social Policy, Public Policy: From problem to practice, Allen \& Unwin, Crows Nest, NSW.

Edwards, Meredith 2004, Social science research and public policy: narrowing the divide, Policy Paper 2, Academy of the Social Sciences in Australia, Canberra.

Kelly, Paul 2005, Presentation to ARACY Conference, 12 August.

Mulgan, Geoff 2003, Government, knowledge and the business of policy making, Keynote address to Facing the Future: Engaging stakeholders and citizens in developing public policy, National Institute for Governance Conference, Canberra, April.

Nutley, S., Walter, I. and Davies, H. 2007, Using Evidence: How research can inform public services, Policy Press, Bristol.

Saunders, Peter and Walter, James 2005, Ideas and Influence, UNSW Press, Sydney.

Shergold, Peter 2005, 'Book launch at annual symposium', Dialogue [Academy of the Social Sciences], vol. 24, no. 3.

Solesbury, William 2002, 'The ascendancy of evidence', Planning Theory and Practice, vol. 3, no. 1 . 